\title{
Por que se faz políticas sociais no Brasil? \\ Notas sobre estratégias de legitimação nos últimos dois governos federais
}

\section{Emil Albert Sobottka*}

A pergunta pelas razões de existirem políticas sociais públicas tem recebido respostas que combinam uma argumentação funcional-pragmática e uma fundamentação ética, perfazendo inúmeras combinações possíveis entre estes "tipos puros". Döring (2004, p. 4), por exemplo, descreveu o fim supremo da política social como "evitar formas extremas de desigualdade e, com isso, assegurar a coesão interna da sociedade". Segundo esta resposta relativamente clássica, estas políticas devem assegurar a continuidade do nível de vida em caso de ocorrência de certos riscos inerentes à vida moderna, como desemprego e incapacidade para o trabalho, e evitar a pobreza. Enquanto a manutenção de um nível de vida já alcançado se orienta pelo mérito, evitar a pobreza implica necessariamente em uma redistribuição de renda. Goodim et al. (2002) mencionam logo seis razões para a existência de políticas sociais: apoiar eficiência econômica, minimizar a pobreza, fomentar a integração e evitar a exclusão social, assegurar estabilidade e fomentar a igualdade sociais e proteger a autonomia individual.

* Doutor em Sociologia e Ciência Política pela universidade de Münster, Alemanha, professor na Pucrs. Esta pesquisa contou com apoio do CNPq. Endereço: sobottka@pucrs.br.

\begin{tabular}{|l|l|l|l|l|l|}
\hline Civitas & Porto Alegre & v. 6 & n. 1 & jan.-jun. 2006 & p. 79-93 \\
\hline
\end{tabular}


Estas mesmas razões são por Kneip (2003) classificadas em econômicas e políticas (funcionais) e normativas (éticas). Sob a perspectiva econômica, a política social serve como estabilizador da conjuntura; na ótica da política ela serve à integração dos distintos grupos sociais e fomenta a lealdade e legitimidade; sob o ponto de vista da ética, ela fornece a justificativa moral para a intervenção do estado na vida dos cidadãos para além dos limites estritamente funcionais de um estado mínimo.

Visto na perspectiva da mobilidade social, cabe à política social a equiparação, até certo grau, das condições de vida, desvinculando a distribuição social das oportunidades da origem das pessoas. Ou seja, ela tem como tarefa fazer com que as características adscritas não se imponham como limitação determinante do horizonte de possibilidades de construção da biografia social.

Estas fundamentações dependem muito do contexto, estão à mercê das mudanças na realidade política e precisam ser constantemente atualizadas. Concebendo-se a sociedade como uma pluralidade de instituições que definem direitos e deveres e distribuem bônus e ônus, então pode-se dizer que nas décadas de 1980-1990 houve um deslocamento do consenso em torno das instituições estruturantes da sociedade em inúmeros países. As instituições que se especializaram no atendimento às concepções éticas, em redistribuir renda, em fomentar solidariedade e atender necessidades e necessitados perderam importância e legitimidade. Cotejados passaram a ser aquelas que incentivam competências ou méritos que possam ser realizadas no mercado. Assim, o balanço entre necessidade e mérito, presente desde o início nos diversos modelos e instrumentos de políticas sociais, deslocou-se e hoje aponta enfaticamente em direção à responsabilidade própria do indivíduo e do seu posicionamento no mercado.

Referindo-se basicamente ao contexto europeu, Esping-Andersen (2004) assim descreve as transformações ocorridas no campo social-democrata do espectro político: o argumento clássico da social-democracia era a domesticação e regulação do mercado,.bem como a limitação de seus efeitos indesejáveis. A idéia norteadora era promover uma redistribuição de renda que fizesse jus às condições sociais do indivíduo. A nova arquitetura do bemestar na Europa, ao contrário, vem sendo fundamentada com o argumento de que ao cidadão devem ser dadas possibilidades para que ele satisfaça suas 
aspirações de bem-estar no mercado. Em outras palavras isto significa que o que se quer é proporcionar ao cidadão aqueles pressupostos que são necessários para ser bem-sucedido individualmente no mercado.

A coincidência entre uma crise mais geral das economias capitalistas e do estado de bem-estar social, o arranjo institucional que se dispunha a prevenir tais crises, foi o estopim que levou tanto a mobilizações políticas como a reflexões acadêmicas que resultaram no fim do consenso anterior em torno da necessidade de determinadas políticas sociais e no deslocamento do balanço entre os seus princípios norteadores. No Brasil historicamente tem sido fraca a tradição argumentativa, mesmo na academia, sobre a fundamentação da política social. O presente texto se propõe a enfocar as mudanças institucionais que afetam aquela política propostas pelos últimos dois governos enquanto projetos distintos de reforma.

\section{Um ciclo de reformas conservadoras e neoliberais}

Na busca de uma explicação para a coincidência entre a crise geral do capitalismo e do estado de bem-estar social, e de uma proposta de solução para ela, foi politicamente bem-sucedido um discurso no qual se uniam o fundamentalismo de mercado e o conservadorismo. Em países como a GrãBretanha, os EUA e a Alemanha, grupos políticos chegaram ao poder no início dos anos 1980 colocando a reforma do estado de bem-estar como ponto central de sua estratégia de governo. Estes grupos eram basicamente compostos por conservadores modernizados, abertos a uma convivência com o liberalismo e o capitalismo, e por fundamentalistas do mercado que atendiam à época por etiquetas como a Escola Econômica de Chicado ou o Consenso de Washington. Para estes críticos da política de bem-estar, os custos crescentes, o efeito de desestímulo das políticas sobre os valores e comportamentos tanto de indivíduos e grupos como também de empresas, e seu resultado considerado desastroso por inchar e imobilizar a administração pública exigiriam uma reforma radicalmente desregulamentadora de toda política social.

Nas reformas propostas, segundo acertadamente argumenta Borchert (1995), o que estava em questão não era prioritariamente encontrar uma solução melhor para um problema dado, mas sim a definição daquilo que é ou não relevante como issue, assim como a questão de quem, como e onde defi- 
ne a relevância das questões. O fato qualitativamente novo era que, nos novos governos conservadores, o objetivo não se resumia a uma mudança de ênfase dentro de um consenso entre todas as forças políticas expressivas, mas uma mudança substancial naquela relação entre política e economia que se cristalizara no Ocidente na forma do estado de bem-estar em meados do século XX. A tarefa civilizatória que as elites tinham assumido para si, e que para elas legitimava políticas sociais e redistribuição de renda (cf. Marshall, 1967; Brakelmann e Jähnichen, 1994), foi renegada em prol de uma ideologia de desempenho e competitividade. Enquanto antes a solidariedade legitimava o empenho da sociedade pelos necessitados, na nova matriz volta-se à tradição puritana de que o necesitado precisa provar que é merecedor do benefício da política social, e que sua situação não se deve a fatores sobre os quais ele tem domínio.

A distância que separava o Brasil, assim como outros países da América Latina, do amadurecimento de um estado que assegure universalmente os direitos sociais de cidadania (Fleury, 1994) não evitou que a crise e clamores por reforma também aqui aportassem (Diniz, 1997) e fossem vitoriosos nas urnas em 1989, com a eleição de Collor de Mello à Presidência da República.

Comum a todos estes grupos políticos é que depois de aproximadamente 10 a 15 anos seu projeto se esgotou e novamente partidos de orientação social-democrata voltaram ao poder. No caso brasileiro, este período se circunscreve entre a primeira derrota eleitoral de Luis Inácio Lula da Silva em 1989 e sua vitória, na quarta tentativa, em 2002. Além de uma razoável defasagem no tempo, há outra distinção a anotar: enquanto, segundo Borchert (1995), os governos dos países desenvolvidos, além de fazer reformas econômicas, também queriam conservar e restaurar determinados valores morais de outrora - o que lhes vale a qualificação como conservadores -, no Brasil esta última componente esteve praticamente ausente. Aqui predominou o fundamentalismo de mercado e os defensores da reforma assumiram um discurso modernizante. Desta diferença resulta mais adequado o uso da qualificação como neoliberal do que como conservador para a polítca de reformas no Brasil.

Muito embora nas democracias seja a regra que grupos políticos concorrentes se alternem no poder, e com isso diferentes programas políticos sigamse um ao outro, esta reforma foi singular pois buscava transformações tão 
profundas e duradouras, que muito dificilmente pudessem ser revertidas. Embora nunca assumido oficialmente, a imprensa brasileira veiculou, no início do governo Fernando Henrique Cardoso, falas do então Ministro das Comunicações, Sérgio Motta, que indicavam que o PSDB teria um projeto de poder de 20 anos.

Os temas colocados em discurso pelos governantes conservadores e neoli berais enfatizavam a necessidade de governabilidade, eficiência e modernização como pressupostos imperiosos de um futuro crescimento econômico; direitos de cidadania, justiça social, democracia e participação, reivindicações ainda feitas por alguns atores sociais, eram relegados a segundo plano ou então ignorados. A diferença entre eles foi assim descrita por Offe (2005):

A controvérsia hoje presente nos meios de comunicação, na academia e entre os partidos políticos acerca do futuro do estado de bem-estar e da seguridade social pode ser qualificada com duas posturas. Uns, a saber os sociais democratas (mais tradicionais) dizem: nós precisamos reconquistar o pleno emprego para poder preservar as conquistas do estado de bem-estar com seus diversos andares. Os outros, os liberais do mercado e muitos conservadores, ao contrário dizem: nós precisamos demolir radicalmente as conquistas e instituições históricas do estado de bem-estar para poder voltar à desejável situação de pleno emprego. Portanto, aquilo que uns querem defender através do pleno emprego é visto pelos outros como o impecílio decisivo no caminho rumo ao pleno emprego!

Estas reformas neoliberais no Brasil interrompem o projeto de ampliação de políticas de bem-estar, que havia sido impulsionado pela Constituição de 1988. Sua expressão não é tanto um corte em programas, políticas ou mesmo em montantes dos assim chamados gastos sociais, mas a recusa de reconhecer como válidos e vinculantes direitos inscritos explícita e inequivocamente na Constituição Federal. Como conseqüência, a utopia de uma sociedade mais justa defendida pelos movimentos sociais também foi se arrefecendo em grande parte da esfera pública, dando lugar ao pragmatismo entre estes atores sociais (Sobottka, 2003b).

Tais reformas assumiram mais o contorno de reforma do estado do que de políticas sociais. Elas reforçaram uma tendência que já havia prevalecido durante o regime militar e tinha as seguintes características: (a) um presidencialismo com Executivo forte, sobredimensionado face a um Legislativo esvaziado e um Judiciário enfraquecido; (b) gestão tecnocrática com predo- 
minância da economia, feita por um círculo restrito de agentes, sobrevalorizando o saber técnico em detrimento da formulação de políticas públicas, enquanto uma parte significativa da burocracia seguia vinculada a práticas de patronagem e clientelismo; (c) reforço de uma cultura política que não confia na capacidade dos partidos políticos e do Congresso de contribuírem para a resolução dos principais problemas do país nem como representantes legítimos da sociedade para controlarem as ações do Executivo; (d) instabilidade jurídica pela imposição de legislação pelo Executivo; e (e) a alta capacidade decisória do Executivo contrastando com a pouca capacidade de implementar decisões e políticas propostas.

Segundo Diniz (2001), a reforma do estado começou já com um diagnóstico equivocado de que, ao lado da crise fiscal, o problema maior seria uma gestão burocrática, e propôs a solução equivocada, a reforma gerencial que fortalece as tendências acima mencionadas. $\mathrm{O}$ mentor deste projeto de reforma, Bresser Pereira (1998; 2001), queria conquistar para esta política organizações civis que fossem geridas segundo a lógica empresarial e vinculá-las com o estado através de instrumentos contratuais negociados com os ministros e seu gabinete, longe dos espaços públicos. Com isso houve, pelo menos até onde foi implementada, uma despolitização das decisões e sua transferência para pequenas elites tecnocráticas. A autonomia dada às agências reguladoras (cf. Moll, 2002), as tentativas de dar autonomia ao Banco Central e a legislação sobre Organizações Sociais e Oscips (cf. Sobottka, 2003a) exemplificam este processo. E ele afeta a própria questão da democracia, pois retira dos espaços políticos - da influência e do controle dos cidadãos - decisões que afetam toda a sociedade. Em especial a política macroeconômica passou a ser definida por tecnocracias indiferentes para com os cidadãos e imunes ao controle do eleitorado.

Os impulsionadores da reforma de orientação neoliberal no Brasil concentraram sua crítica na ineficiência do estado, inclusive para gerir políticas sociais. Ainda que o projeto afetasse profundamente estas políticas, conseguiram evitar assim o desgaste de desconstruir uma fundamentação anterior e de construir uma fundamentação nova para elas. Com isso subtrairam ao debate público e transformaram em questão técnica - de eficiência na aplicação dos recursos - uma mudança paradigmática do universal ao focal nas políticas sociais públicas brasileiras. 


\section{Esfera pública e participação direta como legitimação política}

Em momento algum os portadores da reforma de orientação neoliberal lograram instalar-se em todo o espectro da administração pública no Brasil. Ao mesmo tempo em que detinham o poder em nível federal, havia também estados e municípios importantes governados pela oposição, de orientação social-democrata ou autoqualificada como socialista. As reformas neoliberais coincidiram temporariamente com a introdução de experiências participativas de governo em diversas cidades (Sobottka et al., 2005; Bonfim, 2004). Os impulsionadores das formas participativas de democracia seguiram ocupando o setor esquerdo do espectro político e se opunham, através de iniciativas dos governos locais pela inclusão de movimentos e grupos antes marginalizados, de forma explícita às reformas do governo federal. Em tais nichos locais, mas também em movimentos sociais, conselhos e organizações da sociedade civil, seguia desenvolvendo-se uma esfera pública local (Jacobi, 2002) democrática e participativa, onde o espírito utópico-emancipatório que influenciou decisivamente a constituição do estado de bem-estar seguia vivo (cf. Labra e Figueiredo, 2002). Nos últimos anos este espírito voltou a ter presença mais incisiva na esfera pública através de iniciativas como o Fórum Social Mundial, entre outras, trazendo de volta à agenda política questões pertinentes à justiça social, aos direitos sociais de cidadania, e à democracia.

Tendo como pressuposto que nas democracias as eleições são necessárias mas insuficientes para assegurar um controle adequado dos governantes, seus impulsionadores partiam do pressuposto de que seria cada vez mais patente a necessidade de criar e fortalecer novas formas institucionais de acompanhamento da gestão pública no intervalo entre as eleições, seja no sentido horizontal, entre os poderes, como no sentido da responsabilização frente aos cidadãos. Necessário se faria, segundo eles, repolitizar a gestão pública e reduzir o espaço da racionalidade técnica à sua dimensão instrumental.

Esta nova perspectiva implica estreitar os vínculos com a política, reforçar os instrumentos de responsabilização da administração pública por controle parlamentar, dar mais força à sociedade civil, sem enfraquecer o poder de coordenação do Estado, e diversificar os espaços de negociação e as táticas de alianças envolvendo diferentes atores, associando o aumento da participação com o reforço das instituições representativas (Souza 2001, p. 21). 
A eleição de Lula para a Presidência da República em 2002 foi fortemente associada a uma expectativa de que este ciclo de reformas neoliberais tivesse terminado; esperava-se que, a partir de decisões tomadas dentro de uma nova esfera pública, novamente políticas sociais seriam priorizadas a partir de novas formas de legitimação. Com a eleição chegara ao poder máximo da república o partido que impulsionara a maioria das experiências de orçamento participativo. Além disso, toda a história do partido e do presidente eleito fora construída na defesa da tese de que o foco das políticas públicas como um todo deveria contemplar novamente a dimensão social e que nesta política o critério da necessidade crescesse em importância face ao do mérito. Os programas Fome Zero e Bolsa-Família efetivamente apontavam nesta direção. Contudo, como bem mostrou Santos (2006), este governo perdeu-se em "dilemas [éticos] e labirintos" e buscou equilibrar-se entre uma relação amistosa com movimentos sociais e setores socialmente engajados ao mesmo tempo em que na prática política priorizou inequivocamente a continuidade da política econômica, do loteamento do orçamento do governo entre os diversos partidos aliados e a capitalização político-partidária de uma política que em tese deveria ser de estado.

Poder-se-ia então concluir que os impulsionadores da reforma neoliberal conseguiram o esperado êxito, mesmo que não se mantiveram no poder pelo prazo esperado, tendo tornado sua política na prática irreversível? O grau de continuidade ou descontinuidade entre o governo Lula e seus antecessores precisaria ser investigado por áreas específicas para confirmar ou refutar este tipo de conclusão de forma diferenciada - estudo que não pode ser contemplado aqui. A incapacidade de inovar institucionalmente nas políticas sociais públicas em nível federal, no entanto, parece que pode ser detectada no modo de relacionamento adotado pelo PT e pelo governo com o parlamento e com a sociedade civil. $\mathrm{O}$ incentivo à participação em espaços públicos fomentados pelo governo, que com o orçamento participativo foi uma virtude, em nível federal parece ter resultado inócuo.

As experiências de democracia participativa em governos locais têm sido reiteradamente relacionadas com a criação de uma esfera pública e encontram amparo numa antiga distinção feita por Max Weber. Perguntando-se como o poder era distribuído na sociedade, em seu clássico texto Classe, estamento e partido, ele distingue três âmbitos, cada qual com um tipo de atribuição de poder, ou de lógica, que é acionada pelo agente para dar racionalidade a sua 
ação. Mais dispersa em sua obra, mas mais presente na recepção de Weber pelas Ciências Sociais, é a diferenciação de esferas de valor e ordens de vida em economia, política e cultura. A ação social em cada uma tem um contexto específico que influencia a referência de sentido do agente.

A influência de Weber nessa discussão pode ser vista muito claramente no conceito habermasiano de sociedade, onde é assumida esta mesma distinção (cf. Habermas, 1988, passim). Economia e administração pública são considerados dois âmbitos que historicamente se diferenciaram e segregaram a partir de um todo mais informe. Elas são relegadas por Habermas a um segundo plano por sua condição de (sub)sistemas. Coerentemente com a teoria sistêmica de Luhmann, incorporada neste particular, Habermas espera que os dois subsistemas, mediante sua autopoiese e autoreferência, se encarreguem de reproduzirem e coordenarem-se a si mesmos.

A atenção de Habermas se concentra no âmbito da reprodução cultural, sob o nome de mundo da vida. Não obstante, mesmo recebendo toda a atenção numa obra monumental como a habermasiana, permanece o mundo da vida uma categoria residual que retém aquilo que restou da sociedade após a diferenciação e cisão da economia e da administração pública. A insuficiência desta conceituação parece ter sido intuída, pois o próprio Habermas (ibid., p. 473), ao descrever as formas de intercâmbio entre os subsistemas e o mundo da vida, estabelece uma distinção entre uma esfera privada e uma esfera pública, relacionando-as respectivamente com os subsistemas econômico e político-administrativo. Aos atores sociais agindo segundo a racionalidade comunicativa caberia colocar os limites aos subsistemas.

$\mathrm{Na}$ interlocução de Habermas com seguidores desse enfoque no mundo anglo-saxão, em especial Cohen e Arato (2000), o conceito habermasiano de sociedade é aprofundado. Estes autores diferenciam conceitualmente o mundo da vida numa esfera privada e uma pública, associando a família e a vida privada à primeira, e aprofundando o conceito de sociedade civil relacionado à última. Contribuem assim para desfazer a correlação de origem liberal entre esfera privada e subsistema econômico de um lado, e esfera pública e sistema -de outro. Mas também Habermas, a partir da separação entre trabalho e interação, eclipsa a contradição fundamental da sociedade liberal-capitalista, que se sustenta com base na criação de igualdade formal ao mesmo tempo que produz e reproduz desigualdade material. 
$\mathrm{Na}$ esfera pública do mundo da vida se articula a sociedade civil, da qual fazem parte os movimentos sociais e as ONGs e outros tantas formas de reprodução cultural, para conquistar direitos sociais de cidadania. Este é o genuíno espaço da Política, onde os cidadão, idealmente superando diferenças que causem constrangimento, definem de forma aberta, direta e participativa, os destinos de sua vida em sociedade. Estas definições alimentam a atividade parlamentar e o cotidiano da administração pública.

A essa articulação governos são ora mais, ora menos sensíveis, resultando em maior ou menor oportunidade de participação política. O orçamento participativo, pelo menos em sua forma "clássica", correspondeu exatamente à criação deste espaço de interlocução dos cidadãos, uma esfera pública, cujas deliberações parlamento e governo municipais acolhiam. Dias (2002) mostrou como, nas circunstâncias dadas em Porto Alegre, o parlamento sentiu-se constrangido a acatar deliberações dos cidadãos, enquanto o governo se sentia muito confortável com elas - e capitalizou partidariamente esta situação, criando uma hegemonia política que compensava o fato de ter apenas em torno de um terço dos parlamentares. Em outras experiências de orçamento participativo é possível observar dinâmica semelhante.

A contradição do sistema liberal capitalista, de dar garantia formal e ser incapaz de garantir a materialidade dos direitos sem ferir a própria lógica, apontada por Flickinger (2003), gera uma tensão cujo lugar social de expressão, em tese,.é a política. O estado de bem-estar clássico, que era um compromisso político para amenizar esta contradição, devido à sua estruturação implicava numa tendência à burocratização. Face a ela, a reforma neolibaral e o orçamento participativo formavam pólos opostos: enquanto a proposta de reforma neoliberal buscou despolitizar as decisões em nível federal, experiências locais de orçamento participativo politizavam decisões orçamentárias locais.

Assim o orçamento participativo foi acolhido como vindo ao encontro de tendências recentes no acesso à cidadania. Um estudo de Cox (1998) sobre as reformas aponta para uma mudança muito significativa na concepção dos direitos sociais inerentes à cidadania nas últimas décadas. Segundo ele, esses direitos tornam-se cada vez mais discursivos. $\mathrm{O}$ autor, porém destaca, que isto também torna o poder relativo de articulação discursiva dos interesses das clientelas mais importante do que eventuais necessidades objetivas na distribuição dos 
benefícios. Com isso rompem-se, além do critério da necessidade, dois outros elementos constituintes da tradição dos direitos sociais de cidadania: a universalização e a solidariedade do bem-estar. Esta individualização da política social não apenas facilita a reversão das conquistas da cidadania social, como aponta Procacci (1998), mas recoloca na pauta das discussões atuais o problema da organização dos cidadãos para buscarem seus direitos.

Em nível local, foram os governos que tomaram a iniciativa de organizar esta arena da esfera pública. Isto pode estar em sintonia com as conclusões de Van der Veen (2000), que vê como conseqüência da maior discursividade dos direitos que o futuro exigirá um estado que em sua política social ative o cidadão (activating welfare state). Do ponto de vista da coerência, esta dependência de iniciativas e tolerância governamental contradiz a racionalidade comunicativa que se supõe típica da esfera pública. Experiências como a de Vitória (Sampaio 2006) mostram com é frágil esta inovação democrática enquanto permanece dependente do governo local. Mas, a despeito desta incoerência, quando uma mudança de governo transcende a simples rotatividade dos mandatários típica da democracia e se projeta como uma mudança de projeto de sociedade, como foi no ocaso do ciclo neoliberal em 2002, os eleitores que dão maioria eleitoral também avalizam o projeto que lhes foi apresentado. Em seu programa de governo (PT, 2002), Lula da Silva tinha se proposto a priorizar a política social, dando-lhe novamente o caráter universal, tornando-a o eixo norteador de toda política de desenvolvimento e de investimentos públicos e coordenando através de um conselho com presença transversal em toda política governamental.

Efetivamente, o governo buscou ampliar espaços de participação direta em diversos níveis, em especial criando e incentivando conferências e fóruns de "participação popular". ${ }^{1}$ As inovações institucionais que mais se assemelhariam às experiências locais foram o Conselho de Desenvolvimento Econômico e Social e as consultas para o Plano Plurianual 2004/2007 com seu processo de discussão do Plano Brasil de Todos no ano 2003. Nenhum destes espaços, no entanto, conseguiu cumprir minimamente pelo menos dois requisitos básicos de uma esfera pública fortalecedora da democracia deliberativa

Cf. <www.brasil.gov.br/participacao_popular/>; cf. também: <www.cdes.gov.br/> (Conselho de Desenvolvimento Econômico e Social); <www.planobrasil.gov.br/> (Plano Brasil de Todos e a questão orçamentária). 
ou radical, similar àquela do orçamento participativo local: o próprio governo que os patrocinou não se sentiu vinculado à vontade dos cidadãos ali expressa, nem o parlamento sentiu-se constrangido a acatar deliberações feitas nestes espaços. O governo preferiu seguir outras prioridades e para aprová-las buscou vias tradicionais, intransparentes, para alcançar maioria parlamentar; na perspectiva dos parlamentares, destes espaços de participação popular não emanava uma legitimidade política capaz de render dividendos eleitorais nem de impor desgastes consideráveis por sua inobservância.

Com isso, diferente do que se espera de decisões na esfera pública - e do que ocorre tradicionalmemente no orçamento participativo -, os espaços públicos criados não alimentaram nem o cotidiano da própria administração pública que os incentivava nem.a atividade parlamentar. Assim, o governo, que não se comprometeu a reconhecer como vinculantes os direitos legalmente assegurados aos cidadãos brasileiros nem empreendeu esforço em fundamentar discursivamente a prioridade prometida para a política social, tampouco conseguiu ser inovador em nível federal como o foi seu partido anteriormente em nível local, e criar um equivalente funcional para a esfera pública, de onde emanasse uma nova política social. Acabou seguindo uma política econômica neoliberal, subtraída do controle político dos cidadãos com a autonomia de fato do Banco Central e do Copom e com a priorização absoluta da geração de recursos para o serviço da dívida, e preservou intactas as estruturas tradicionais (e como se viu através dos sucessivos escândalos envolvendo negócios excusos com recursos públicos, também doentias) de decisão sobre os investimentos sociais. E este modo de fazer política social não se legitima com argumentos passíveis de debate público - fossem eles funcionais ou normativos.

\section{Referências}

ABERS, Rebecca. Practicing radical democracy: lessons from Brazil. Disp - Zeitschrift des Netzwerks Stadt und Landschaft (NSL) der ETHZ, v. 147, 2001, p. 32-38.

BONFIM, Washington. O aprofundamento da democracia no Brasil: tendências, conflitos e dinâmica. Civitas, v. 4, no 1, jan.-jun. 2004, p. 73-94.

BORCHERT, Jens. Die konservative Transformation des Wohlfahrtsstaates. Frankfurt: Campus, 1995. 
BRAKELMANN, G. e T. Jähnichen. Die protestantischen Wurzeln der sozialen Marktwirtschaft: Ein Quellenband. Gütersloh: Gütersloher Verlagshaus, 1994.

BRESSER PEREIRA, Luiz Carlos. Da administração pública burocrática à gerencial. In: Bresser Pereira, Luiz Carlos e Peter Spink. Reforma do estado e Administração Pública Gerencial. Rio de Janeiro: Fundação Getúlio Vargas, 1998, p. 237-70.

— et al. Sociedade e estado em transformação. São Paulo: Unest, 2001.

CALHOUN, Craig. Habermas and the public sphere. Massaschussets: Mit Press, 1996.

COHEN, Jean L. e Andrew Arato. Sociedad civil y teoría política. México: Fondo de Cultura Económica, 2000.

COX, Robert H.. The consequences of welfare reform: how conception of social rights are changing. Journal of Social Policy, v. 27, $\mathrm{n}^{\circ}$ 1, 1998, p. 1-16.

DIAS, M. R.. Hegemonia e polarização. A reconfiguração de forças políticas no município de Porto Alegre (1988-2000). Civitas - Revista de Ciências Sociais, v. 2, n. 1, 2002, p. 157-179.

DINIZ, Eli. Globalização, reforma do estado e teoria democrática contemporânea. São Paulo, São Paulo em Perspectiva, v. 15, n. 4, out.-dez. 2001, p. 13-22.

. Crise, reforma do estado e governabilidade: Brasil, 1985-95. Rio de Janeiro: Editora da FGV, 1997.

DÖRING, D. Sozialstaat. Frankfurt am Main: Fischer, 2004.

ESPING-ANDERSON, Costa. Die drei Welten des Wohlfahrtskapitalismus: zur politischen Ökonomie des Wohlfahrtsstaates. In: Lesseich, Leplan e Ostne, Ilona. Welten des Wohlfahrtskapitalismus. Frankfurt am Main: Campus, 1999.

Die gute Gesellschaft und der neue Wohlfahrtsstaat. Zeitschrift für Sozialreform, v. 50, $\mathrm{n}^{\circ} 1-2,2004$, p. 189-210.

FLEURY, Sônia. Estado sem cidadãos: seguridade social na América Latina. Rio de Janeiro: Fiocruz, 1994.

FLICKINGER, Hans-Georg. Em nome da liberdade: elementos da crítica ao liberalismo contemporâneo. Porto Alegre: Edipucrs, 2003.

. Movimentos sociais e a construção do Político: Carl Schmitt. Civitas, v. 4, no 1, jan.-jun. 2004. p. 11-28.

GOODIN, R. E., B. Headey, et al. The real worlds of welfare capitalism. The welfare state: a reader. C. Pierson e F. G. Castles. Cambridge: Polity Press, 2002, p. 170-188.

HABERMAS, Jürgen. Die neue Unübersichtlichkeit. Frankfurt am Main: Suhrkamp, 1985. 
1988.

. Theorie der kommunikativen Handelns. 2 v. Frankfurt am Main: Suhrkamp,

JACOBI, Pedro R. Políticas sociais locais e os desafios da participação citadina. Ciência \& Saúde Coletiva, São Paulo, v. 7, n. 3, 2002.

KNEIP, S. Die sozialphilosophischen Grundlagen des demokratischen Wohlfahrtsstaats. Welt Trends: Zeitschrift für Internationale Politik und Vergleichende Studien, v. 39, 2003, p. 11-29.

LABRA, M. E. and J. S. A. d. Figueiredo. Associativismo, participação e cultura cívica. O potencial dos conselhos de saúde. Ciência e Saúde Coletiva, v. 7, n 3, 2002, p. 537-547.

MACKERT, Jürgen. Jenseits von Inklusion/Exklusion. Staatsbürgerschaft als Modus sozialer Schliessung. Berliner Journal für Soziologie, Berlin, n. 4, 1998, p. 561-576.

MARSHALL, T. H.. Cidadania, classe social e status. Rio de Janeiro: Zahar, 1967.

MOLL, L. H. (org.). Agências de regulação do mercado. Porto Alegre: Ufrgs, 2002.

MORAES, Reginaldo C.. Reformas neoliberais e políticas públicas: hegemonia ideológica e redefinição das relações estado-sociedade. Educação e Sociedade, Campinas, v. 23 , n. 80 , set. 2002 , p. $13-24$.

OFFE, C. (2005). Princípios de justiça social e o futuro do estado de bem-estar social. In: D. G. d. Souza e N. Petersen. Globalização e Justiça II. Porto Alegre: Edipucrs, p. 69-85.

PARTIDO DOS TRABALHADORES. Programa de governo 2002. Disponível em: www.pt.org.br/, 2002. [Acesso: abr. 2006].

PROCACCI, Giovanna. Arme Bürger: soziale Staatsbürgerschaft versus Individualisierung von Wohlfahrt. Berliner Journal für Soziologie, Berlin, ํㅡㄴ, 1998, p. 73-88.

SAMPAIO, Ana Paula S. Orçamento participativo de Vitória: analisando o formato institucional. Civitas, v. 6, n $1,2006$.

SAMUELS, David: From socialism to social democracy: party organization and the transformation of the Workers' Party in Brazil. Comparative Political Studies, 2004, p. 1-26.

SANTOS, Hermílio. Política social no governo Lula: dilemas e labirintos. In: Dias, Marcia R. e Perez, José Manuel S. Antes do vendaval. Porto Alegre: Edipucrs, 2006 (no prelo).

SARLET, Ingo W. Dignidade da pessoa humana e direitos fundamentais na constituição de 1988. 2ª ed. Porto Alegre: Livraria do Advogado, 2002. 
SOBOTTKA. Emil A.. Participação na reforma administrativa brasileira. In: Clarissa E. B. Neves e Emil A. Sobottka, Sociologia, pesquisa e cooperação. Porto Alegre: Ed. Universidade - Ufrgs, 2003a, p. 151-167.

. A utopia político-emancipatória em transição: movimentos sociais viram ONGs que viram "terceiro setor". Teoria e Sociedade, v. 11, no 1, jan.-jun. 2003b, p. 48-65.

Orçamento participativo: conciliando direitos sociais de cidadania e legitimidade de governo. Civitas, v. 4, noำ 1, 2004 jan.-jun., p. 95-110.

SOBOTTKA, Emil A. et al.. Social research as political mediation: reflections on the participatory budget. Concepts and Transformation: International Journal of Action Research and Renewal, $\mathrm{n}^{\mathrm{0}}$ 1. 2005.

SOMMERS, Margaret R.. "Citizenship" zwischen Staat und Markt. Das Konzept der Zivilgesellschaft und das Problem der dritten Sphäre. Berliner Journal für Soziologie, Berlin, n. 4, 1998, p. 489-505.

SOUZA, Celina. Construção e consolidação de instituições democráticas: papel do orçamento participativo. São Paulo em Perspectiva, São Paulo, v. 15, n. 4, out.-dez. 2001.

VAN DER VEEN, Romke. Reflexive modernization and social solidarity: notes on the future of the modern welfare state. The Netherlands Journal of Social Sciences. Van Gorcum, v. 36, n. 1, 2000, p. 89-105.

Recebido em 28 de janeiro de 2006 e aprovado em 15 de fevereiro de 2006 